\section{An Autress}

\author{
on
}

\section{FIFTY YEARS OF MEIDICAL EDUCATION.}

Delivered at the Opening of the Winter Session at King's College, London."*

By ALEXANDER MACALISTER, M.D., F.R.S., PROFESSOR OF ANATOMY IN THE UNIVERSITY OF CAMBRIDGE.

In point of time this academic year is remarkable as being the jubilee of the publication of the most epoch-making book of the nineteenth century, Darwin's Origin of Species. It is not too much to say that this work has led to the reconstruction of the philosophy of biology, and its influence is widely felt in many other departments of knowledge. This year is also the jubilee of the issuing of another treatise, Humphry on The Human Skeleton, which, though much more modest and special, may yet justly be termed a monumental work. Perhaps in the rapid succession with which new manuals of anatomy are now being sent forth from the press, this book may not be known, by name even, to twentieth-century students; yet it has been to me the most interesting and stimulating work on that science that I have ever read. It was the first book on osteology that was put into my hand when, on October lst, 1858, just half a century ago to-day, I attended my first introductory lecture.

While on the theme of jubilees, it is worthy of note that in 1858 Pasteur completed his researches on vinous fermentation, and confirmed the earlier observation of Cagniard de la Tour, proving that this process was the work of a micro-organism. This was one of those remarkable preliminary studies which eventually led to that greatest of all generalizations in medical and surgical science, the germ theory of disease, which has done for the practice of our profession what Darwin's book did for biology. In that year, also, Lister published in the Philosophical Transactions one of the most important of the remarkable series of memoirs which have revolutionized surgery. The paper was a study of the early stages of inflammation.

This year is also the jubilee of another momentous historical event, the passing of the Medical Act, which is in some sort the charter of the profession. This Act was the instrument whereby was instituted the General Medical Council. Whatever diversity of view may be entertained as to the sufficiency of the powers which the Act placed in the hands of this our professional parliament, it was important as a public recognition of the need of an official representative body to advance the interests of medical education, and to safeguard the rights of the qualified practitioners of medicine and of the public. It is to a large extent due to the guiding wisdom of this body that greater changes and developments have taken place in the curriculum during these fifty years than in the two preceding centuries. In my student days we had no histological or physiological laboratories worthy of the name. Pathology was limited to naked-eye morbid anatomy, the very name of bacteriology was unknown, and most of our hospitals were unreformed, for it was before the passing of Mrs. Gamp and the advent of the ward sister. Our course was nominally for three years, but, as this was interpreted at the Dublin College of Surgeons as meaning three winter sessions, the diligent man could present himself for his final and only examination two years and six months after entry. In the University of Dublin the course was nominally one of four years, but by a pleasing fiction the student could, if he desired and if his tutor was complaisant, pass his entrance examination the day before the final examination of his junior fresh. man year, thereby becoming at a stroke a second year's man. I remember taking advantage of this method of abbreviating my course.

In our first year we attended lectures on chemistry, anatomy, physiology (or the stuff that was called by that name), and surgery; and in the first summer session we took chemistry, botany, and materia medica. We were *A few passages have been omitted owing to considerations of space. expected also to spend three hours a day in the hospital wards. In the second we dropped chemistry and took practice of medicine, and in the second summer medical jurisprudence and obstetrics. In those days, however, roll call was a custom more honoured in the breach than the observance, and in consequence the actual attendance at some of the classes was scanty; but the certificate could be obtained by any one who paid the fee, and that was all that was essential. In the third year we took, or at least paid for, the same courses again, and were signed up by April 1st. There was no instruction in physics.

One laboratory course we had which was continued throughout all three winter sessions-practical anatomy; and as we were able to dissect the whole body in the course of each session, it was our own fault if we did not learn the macroscopic anatomy of man thoroughly. In the dis. secting room in which $I$ worked, however, we were largely left to our own devices with little or no supervision, and as our textbooks were indifferent $I$ fear that many of us did not profit by our opportunities as much as we ought to have done.

In operative surgery our bugbear was haemorrhage, not sepsis. We learned by experience that the quicker an operation was performed the better were our results, so in this respect our anatomical knowledge was of great practical advantage, and as bodies were generally abundant we had ample opportunities of practising on the cadaver. I remember at a later time before my first lithotomy I performed the operation fifteen times on the dead body. I have a vivid memory of helping in operations performed in a phenomenally small number of seconds.

Before the days of Lister abdominal surgery was practically taboo. The opening of the peritoneal cavity was nearly certain to be followed by peritonitis and usually by death, and there were few major operations in which the wounds healed without suppuration. Now, thanks to the discovery by your great and revered emeritus professor, there is no corner of the human body which may not be invaded by the surgeon's knife and finger, when disease or accident requires such intervention; and this can be, and is done not only in your large metropolitan hospitals, but in country villages, wherever the conditions of asepsis or antisepsis can be ensured. I have seen complicated colotomies, gastrostomies, and other abdominal operations performed with as signal success and as rapid recovery in a remote Chinese village, in Syrian towns, and on shipboard, as in London or Tokyo.

In medicine, as well as surgery, we were half a century ago not much more than emerging from mediaevalism. In the absence of helps to physical diagnosis such as the thermometer or the microscope, we were thrown back on minute and close observation of objective phenomena and of the specific physiognomy of the several diseases, but we felt ourselves surrounded by mysteries, as we had no fundamental or unifying hypotheses as to the nature of pathological processes. In my last year of student life I learned of the researches of Virchow, whose "cellular pathology," with the works of Lister, Simon, Pasteur, and the other pioneers of that period, formed the starting point of a scientific pathology.

In our anatomy also we were without any morphological interpretation of structure; the transcendentalism of Goethe was unsatisfying and seemed a chimera. Owen's archetypal theory was based on what we felt to be an obvious fallacy. Lamarckian evolution was discredited; those of us who cared for such things were too good Cuvierians to adopt it; and Darwinism did not filter into the teaching during my student days, and when, as Demonstrator, I introduced evolutionary doctrines of interpretation, I was regarded with suspicion as heretical.

At the end of our course we were not troubled with practical or written examinations. At the Irish College of Surgeons the student sat at a table with the examiners, each of whom in turn questioned him for a quarter of an hour. This process lasted for an hour each day for two days, and at the end the chairman informed him whether he had passed or no. Obviously an examination of this nature played into the hands of the "grinder." At Trinity College a written examination had been introduced two years before, but it was nominal rather than real up to the middle of the Sixties, and in 1858 they had also a practical examination of a very rudimentary description. In this, as well as the oral examination, the candidates sat together 
in a class, and the question missed by one was passed on to his neighbour. At one examination at which $I$ was present shortly after the introduction of the practical examination, the candidates were successively asked to find the semilunar ganglia, which they all failed to do. At one written examination that I well remember the invigilator, after giving out the papers, turned his back on the candidates, opened a newspaper, and took no notice of the textbooks and memoranda that were freely used. The entire examination lasted two days.

You students of the present day have no such primrose path to a qualification. Each decade since has witnessed a lengthening of the course, an increase in the number of subjects of examination, and a greater stringency in the standard required. This development of the curriculum is the product of a Darwinian process of evolution, and the result is the survival of the tittest as regards both the students themselves and the subjects of examination, in the more strenuous struggle for life.

The modern curriculum is an attempt to realize a scientific ideal. Its three stages mark the progress from the general fundamental sciences to the particular application of their principles, and at every stage practical work goes hand in hand with the teaching of theory. The result is that, even with the present five years' minimal course, anatomy, instead of being, as it used to be, the one dominant subject of drill, has to take its place as one out of five sciences in which laboratory work has to be done. This I lament as a misfortune, the more so as the develop. ment of surgery requires a more precise topographical knowledge of many parts that we used to regard as out of the reach of operation, while also the subject has become one of greater complexity in details, as any of you can find out by comparing the textbooks in use fifty years ago with those of to-day. The enormous developments of the range of knowledge, and the practical nature of the methods employed in teaching the other sciences, has rendered this diminution inevitable. The addition of these new elements to the course is imperative, for there is no other profession in which the knowledge of so many fundamental sciences is inexorably necessary. The practice of medicine and surgery has this distinguishing characteristic - that members of our profession, whether they like it or no, are engaged in what is essentially original research during the whole of their lives, and they ought to be adding continually to their own knowledge, and to the general fabric of medical science. No matter how many degrees or diplomas you obtain, you can never cease being medical students.

In the length of the course and the variety of its elements is its strength, for the curriculum is constructed so as to afford a base wide enough to be an adequate foundation for your life-work, and neglect of any part is sure to prove a source of weakness; for if the foundation be not well and truly laid in each particular, it will inevitably lead ta subsequent settlements and dislocations in the superstructure.

These fundamental scientific studies-physics, chemistry, biology, anatomy, physiology, and pathology, including bacteriology, are each of prodigious and growing extent. No man can hope to master them all; indeed, in these days of specialization, it is difficult for any one to become conversant with the whole range of any one science as it ought to be known. I speak feelingly, for in the one science which I have been teaching for the last forty-eight years it seems to me that I am only now beginning to compreh $\in \mathrm{n}$ the depth of my ignorance. It is necessary that in the case of each a selection must be made whereby special emphasis is thrown in the teaching on those parts essential to your life-work. In other words, it entails teaching by schedule either explicitly, as in physics, chemistry, and biology, where certain parts are categorically described; or implicitly, as in anatomy and physiology, where, as the subjects are too vast to be taught in their entirety, the teacher must select those parts on which particular stress is laid. In making these selections the two determining factors are: First, that it should represent and illustrate the fundamental principles of the science; and secondly, that it should have a constant and thorough reference to the end for which the sciences are being learned, the prevention and treatment of disease and acc.den:

Sciences which are so large and so rapidly increasing must be taught by specialists who devote their lives to their respective subjects, and in this there is an advantage and a danger. An advantage, because he who knows best must speak with the greatest authority. The student cannot verify every statement, and must take a great deal in faith on the word of his teacher. The danger is that it often happens that the facts of the science most interesting to the specialist are those which are of the least value to the practitioner. To take a concrete case : Anatomy is of necessity one of the most important of these sciences, and no man is fit to practise medicine who does not know the structure of the human body; but there are aspects of anatomy, especially on the morphological side, which rarely, if ever, serve any useful purpose in practical medicine or surgery. The general principles of morphology are important, as they form the only memoria tecknica which makes anatomy a science, and a knowledge of these principles redeems anatomy from being, as it used to be a disconnected set of isolated and apparently irrelevant facts. But the teacher must sternly put upon himself a wise restraint in the selection of the essentials, passing over that which is chiefly or wholly of academic interest. This is a consideration so important that I have reiterated it now, although I know I have discussed it elsewhere on a somewhat similar occasion, and it is one which I would earnestly commend to the notice of examiners, for with them lies the last word as to what a student in his state of probation is expected to learn. This restraint also applies to the other sciences, especially to embryology and physiology; and in after-life that student will bless or curse his teacher according to the wisdom with which this guiding principle regulates his schedule-making. It follows as a corollary that the teacher is heavily handi. capped if he has not had personal experience of the needs of the student by having gone through the whole of the medical course. I should not feel myself fit to teach anatomy if I had not behind me the experience of ten years, both in private practice and as one of the surgical staff of a hospital. Pathology and bacteriology are sciences in which it is not safe to allow of any selection. They must be studied in their entirety, as they bear on professional problems at every point.

The process of Darwinian evolution has eliminated certain elements from the curriculum. Thanks chiefly to the vigorous denunciations of Professor Huxley, that multifarious farrago of useless knowledge which used to be taught as materia medica has been minimized and purified into a scientific pharmacology. In my student time we had to learn heterogeneous details as to the source of each drug, the genus and species of each medicinal plant, and other useless information, but were not obliged to have any practical experience of compounding. Before 1864, when the British Pharmacopoeia was issued, we had the additional burden of remembering the relative strengths of a number of officinal preparations according to the London, Edinburgh, and Dublin Pharmacopoeias respectively. The unification of these into the British Pharmacopoeia and the steady improvement in each successive edition of that work has been all in the direction of lightening the burden on the student's memory.

Another course that has been eliminated in the evolution is botany. This was a survival of the days when the physician was a herbalist. At a time when branches of practical work were few, botany had its advantages, for the mental process whereby we used to note the distinguishing characters of a plant so as to refer it to its proper genus and species is practically an exercise of the same order whereby, when confronted with a patient, you work out the diagnosis of his disease. Fortunately, perhaps, for you, botany is gone, but personally I am glad that it was a part of the course of my student days, and my little knowledge of it has been a source both of interest and advantage in some of the out-of-the-way corners of the world which it has been my hap to visit. The botany we used to learn was systematic, not physiological. It had one great charm - that it was partly given al fresco, and entailed lessons in the botanic garden and botanical excursions to those neighbouring places where the flora was richest.

While the selective method of teaching is a lamentable necessity on the part of the teacher, it has also its dis- 
advantages from the student's standpoint. The schedule is an artificial grouping of parts of the sciences put together so as to make a coherent whole. Of necessity the teaching must be magistral and peremptory: Difficulties are elided and whole sections of each subject are necessarily ignored. The more intelligent student easily comprehends that this is so, but it is possible that others may misconceive the proportional relation between the selected portions taught and the entire sum of knowledge. As the schedule is prepared for a special purpose, the perspective of the facts and principles taught is different from that in which they would appear if the science were being studied for its own sake. In a familiar passage in the Advancement of Learning, Bacon deprecates this method of using knowledge solely to the end of applying it to lucre and professional work. "I am not ignorant," he says, "how much that diverteth and interrupteth the prosecution and advancement of knowledge like unto the golden ball thrown before Atalanta, by which, while she goeth aside and stoopeth to take it up, the race is hindered." One must impress upon the student that the schedule represents much less than the present actual knowledge, which is itself probably only an infinitesimal fragment of reality.

Another pitfall in the partial study of any science is that it encourages the misuse of hypothesis. It is needful to teach fundamental hypotheses in order to group the facts you learn; but even the best hypotheses are all diagrammatic artefacts, framed by abstraction from the sum of the part of reality which is known, valuable as far as they go, and if valid, suggestive of new lines of research. We had such fundamental hypotheses in chemistry and physics. We were taught the atomic theory, and in some misty way the conservation of energy and the correlation of the physical forces. These concepts gave to the physical sciences a definition which was wanting to the biological.

I well remember the advent and development of the modern forms of the evolution hypothesis, and its recognition as the great nexus whereby the jumble of biological, and especially of anatomical, facts became associated to form a scientific morphology. Under the influence of that "Idol of the Tribe," the passion for unification, we at first fondly supposed that all biological problems were in a fair way to be resolved; and in the light of the physicochemical discoveries which were being made in experimental physiology, we dreamt of explaining all the phenomena of life in terms of matter and force. We saw momentous differences in properties traceable back to trifling alterations in the amount and combinations of elements, and were disposed to regard these internal states, such as sensation and consciousness, as indirect effects or concomitants of physical processes, considering them as a kind of reflexion within us of the material changes taking place in the nervous systems. To the most of us now that phase has passed, and the physico-chemical hypothesis of life and organization has been weighed and found wanting. The grounds of this rejection have been in part lately and forcibly set forth by Mr. Haldane in his recent presidential address to the Physiological Section of the British Association, where you will find a fair and clear statement of the need to assume the existence of an independent factor in the processes and organ-building of living beings. I had intended to speak at some length on this topic, but it has been so well dealt with in that address that $I$ need do little more than commend it to your careful perusal. It will be found in the British Medical Journal of September 12th. I may add, however, that from the standpoint of pure anatomy there are considerations quite as cogent as those from physiology which render the physico-chemical theory untenable as a valid or even credible ground on which to interpret the phenomena of morphology.

One illustration of this we may take from the structure of the nervous system. Our knowledge of the structure of the brain has of late years made prodigious strides. Three centuries ago all that was known of the cerebrum was, in the words of old Burton, in his Anatomy of Melancholy (1641), that "it hath many concavities distinguished by certain ventricles, which are the receptacles of the spirit, brought hither by the arteries from the heart, and are there refined to a more heavenly nature, to perform the actions of the soul. Of these ventricles there are three-right left, and middle. The right and left answer to their site and beget vital spirits; if they be anyway hurt, sense and motion cease. The middle ventricle is a common concourse and cavity of them both and hath two passages, one to receive pituita, the other extends into the fourth creek; in it they place imagination and cogitation, and so these three ventricles of the forepart of the brain are used."

A hundred years later, Leeuwenhoek, by the aid of a simple microscope, discovered that the grey matter was made up of what he called globules; in opposition to the view of his fellow-countryman Ruysch, that it was a congeries of blood vessels.

Sixty years later Prochaska described, although in a very imperfect manner, the cells of the grey matter, and propounded the theory that the vis nervosa was inherent in this brain pulp with its granular corpuscles. As the microscope became perfected, these nerve cells were more clearly seen, and described more carefully in the beginning of the nineteenth century; but by the new histological methods introduced during the last quarter of a century, we have obtained clearer and more adequate views of the structure and complexity of the nerve cell.

A good summary of the present state of knowledge has been given by Professor Retzius in his Croonian Lecture, delivered last May and published last week. We now kwow that with its differentiated processes, its definitely organized reticulum, and definitely arranged granules of various nature, its nucleus and nucleolar network and chromatic filaments, the neurone is the most complex unit in the human body. All that is known, however, is little more than what may be called the gross anatomy of the neurone; but there is behind what we see a definite molecular organization, which must exist, although it is beyond our ken. The many thousands of molecules of various materials which go to make up each. individual neurone must be specifically arranged in order to produce the characters that we see; and each of these invisible molecules is itself a structure of amazing complexity whose ultimate constituent units are beyond our powers of numeration. Thus each neurone is in itself a far more complex organism than any other unit in the body; and, as known to us, each neurone is more intricate in structure than the whole cerebrum was supposed to be in the prehistological period. This is only the first step. There are millions of these neurones in the cerebral grey matter, and these are not placed fortuitously, but they are definitely arranged, and, according to the current hypothesis, each neurone is a separate organization. There is in each part of the grey cortex a specific architectonic plan, according to which these cells are placed.

When 1 was a student there were only five convolutions, which were named. All the rest were supposed to be vague and inconstant. Gradually the scheme of the definite arrangement of these gyri over the whole surface of the cerebrnm has been discovered and mapped, and the histological topography of each examined, with the result that the characteristic arrangement and varying form and structure of the neurones in each of the many subdivisions of the cortex is now definitely known. In place of the brain pulp of Prochaska we have a definite array of convolutions, each with its specifically-grouped cells, and each of these with its definite support apparatus, and with its processes in constant and regular relation to the processes of their neighbour cells. These cortical neurones are regularly related to those others which build up the central ganglionic masses, but the intricacy of those relations baffles our powers of observation, and yet this wonderful assemblage of orderly-disposed cells is so grouped that the whole assemblage can function as a physiological unit.

But the crowning mystery of all is that this incomparably complicated apparatus has grown up out of an infinitesimally minute fraction of a single germ cell-the ovum. We can watch this process of embryogenic evolution and can see the several parts built up, but we stand amazed at the sight. This germ cell receives no other material to nourish it during its growth, maturation, and development than that which the parent has elaborated out of the bread and butter and beef of her foodstuff; and yet it not only develops this apparatus and all the equally intricate subsidiary arrangements in the body connected with it, which it is the function of the nervous system to correlate, but it also becomes built up so as to become eventually identical 
with the parental nervous system. The mystery is enormously enhanced by the fact that the parental nervous system has had nothing to do at any stage with the genesis or growth of any of the elements of the germ cell itself. There is more at the back of this evolution than a physico-chemical action. Evolution is the name we give to the modal process of growth, but we are left where we were as regards the mystery of origins or of the forces by which this process is brought about and directed.

But if the physico-chemical hypothesis is incompetent to account for the mysteries of organization, it is stil more inefficient as an explanation of the psychological processes of consciousness. This is too large a theme for us to enter upon here and now. I will only say in passing that it seems to be one of the strangest phases of human thought that we should ever have been brought to entertain any doubt of the existence of our own minds. In the last analysis the only existence of which we have direct experience is our personal consciousness. To deny the existence of that which we know directly, and to regard it at second hand as a product of the materia nature, which we only know indirectly and by means of the knowledge in that very mind itself, simply leads to a universal nescience.

I do not under-estimate the far-reaching value of the theory of evolution. As a modal and heuristic hypothesis it enables us to comprehend much of the past history of organic nature that would otherwise be incomprehensible but when we array all that we know of the development of living forms, we see that the organic world has, from its beginning, been moving harmoniously onwards step by step towards its present order, along with a course which to us who view the result after the event now appears to have been inevitable. Nowhere has it been apparent at any stage what the future order is about to be. No genera tion plays its part because it knows what will be the out coming result, yet that result is a well-ordered cosmos, not a chaos, and is only intelligible on the hypothesis that behind all these there is a continuing mind in whose thought all these actors and their several parts are perfectly forecast and related.

It is not only in biology that hypotheses have to be used as the servants, not the masters. In the more recent physical science there is, at present, in view of the many startling new developments, a need for the revision of the fundamental hypotheses, and just as the veteran physiologist summed up the probable future of his science in the word ignorabimus, so we find an eminent physicist forecasting that the future of physical science may be something of which now we have absolutely no conception.

I have made this long and, I fear, wearisome digression to emphasize the care with which hypotheses should be used in our scientific studies. They are at best fingerposts, and we must be careful to avoid confounding the hypothesis with the phenomena that the hypothesis is supposed to correlate. Nature is immeasurably greate than our most advanced conception of it, and it is Nature we are to study, not merely the diagrammatic representa. tion of it. We have to deal with facts, and it will be your business to make yourself familiar with them, and to remember that in your work you are really doing original research. That body which you are about to dissect you will find does not in all details conform to the book description. It has characters of its own that you ought to note; just as each patient you will see in after-life shows his own idiosyncrasies, of which you must take account. You have, therefore, now to learn to observe and to register phenomena. But this direction is easier for me to give than for you to take. There is no faculty of the mind that requires or repays careful cultivation more than this power to observe correctly and critically, and it is one which at the present day is often atrophied from want of use. The student now is spoon-fed by his teacher; he is provided with excellent and sumptuously-illustrated textbooks, so that he can assimilate knowledge of a kind with. out exercising any independent power of observation. He is told what he ought to see, and consequently sees it. It was different with us in the middle of the last century. Our textbooks were poor, and often with few or no figures, and consequently we had either to make out all the structures for ourselves with very little external help, or to be satisfied with the unintelligent absorption of the cut- and-dried dictum of our grinders. The former process was: slow, but it was an effectual method of learning. Now, there is an almost irresistible tendency to see with the eyes of our teacher, not our own, and in consequence the kind of knowledge that is acquired too often makes but a transient impression on the memory.

This also reacts on the power of description. It ceases to be spontaneous and original. The student, from the very elaborateness of his helps, can only recall phenomena in the words of his lecture or textbook. That condition is one which is perfectly familiar to all examiners, and the diligent reader of the medical journals cannot fail to note that the critical faculty of description is occasionally not acquired even after qualification. Now, at the outset of your career, is your time to educate yourselves, by practice in observation without your textbook, and in the art of describing what you see in your own language. Check it afterwards if you will by your book, but do the work first yourself, and if you carry out this process in your laboratory and ward work, in after.life you will be able to set forth clearly, tersely, and accurately what you have observed.

This habit will help you in the ordeals that await you in the near future, your examinations. In writing your papers, if you wish to earn the good will of your examiners, bear in mind Billings's three golden rules for medical writers: (1) Don't write unless you have something to say; (2) say it; (3) stop when you have done. In afterlife, when you come, as I hope most of you will, to the stage of publishing your observations, keep these rules in mind, and to them I would add as a fourth Whewell's advice, "Verify your references." If only these rules were borne in mind in the ordinary medical journals we should not have to wade through mountains of chaff to pick up the few grains of new truth.

And now in conclusion, it is my duty to say a word of welcome to those of you who are beginning your professional studies. You have hard work before you, but it is worth doing. Five years may seem a long time to look forward to, but it is little enough to equip you for your professional career. The profession you seek to enter is crowded, but there is always plenty of room at the top, and those who are the fittest to survive in the struggle for life will find their way to attain that level. Some of the factors of this struggle we know, and your relation to them is in your own hands. Two of these, the most important, you have absolutely in your own control. These are, knowledge of your profession, and personal character. You have now and here the means of acquiring the first, and it will be your own fault if you do not succeed in mastering it. You have also in your own hands the building up of your own character in uprightness, straightforwardness, conscientiousness and sympathy (real, not sham), with those whom you have to treat in after-life. A third factor is common sense. Well, if you have not that by nature, you may by care and attention and mental discipline improve in this respect. But there are many who, if Burton be right in his localization, must have very small lateral ventricles in their brain.

To those who have begun their work and who to-day have their efforts rewarded by prizes, I need only say, persevere. You have begun well and have earned distinction among your fellows, and ought therefore to be in the fair way towards success. But these attainments are only a preliminary step towards that success. If you have read the story of Sordello, as given in Browning's wonderful psychological phantasmagoria, you will remember how he achieved his first triumph, which was so signal that his competitor Eglamor died of the vexation of defeat; but when later he was brought face to face with the crisis of his life, when a brilliant future of power was put within his reach, the poet has with marvellous skill unfolded before us the tangled web of indecision and lack of firmness of purpose which culminated in his miserable failure.

No man can succeed in our profession unless he has acquired an honest self-reliance based on an exact knowledge and a true estimate of his own powers and capabilities, as well as on a consciousness that he is in the path of duty. Such a frame of mind is wide as the poles asunder from self-conceit. . Browning has given us in another of his poems, "Paracelsus," a lurid picture of the moral and physical shipwreck of a noble mind led away by overweening vanity and self-conceit. These are two beacons on dangerous shoals. In medio tutissimus ibis. 